\title{
Weaning from mechanical ventilation in the elderly postoperative cardiac surgery patient
}

\author{
J. A. Romand and P. M. Suter \\ Division des Soins Intensifs Chirurgicaux, Département d'Anesthésiologie, Hôpital Cantonal Universitaire. \\ Genève, Switzerland
}

KEY WORDS: Mechanical ventilation, weaning, cardiac surgery, elderly, postoperative.

\section{Introduction}

The immediate postoperative period is crucial for the readaptation of the cardiovascular and respiratory system to a number of pathophysiologic changes induced by surgery and the extracorporeal circulation. The incidence and the severity of postoperative morbidity can be improved substantially by an appropriate respiratory support and oxygen delivery to the myocardium and other organs ${ }^{[l]}$.

\section{Postoperative respiratory problems}

The most important and constant changes in respiratory function following cardiac surgery are: (1) an acute restrictive pulmonary disorder with a decreased functional residual capacity and decreased pulmonary and total respiratory compliance $^{[2]}$; and (2) interstitial pulmonary oedema, mediated by complement activation and accumulation of granulocytes in the pulmonary capillaries $^{[3]}$. In addition, a number of other factors can be involved in postoperative respiratory dysfunction (Table 1).

Postoperative respiratory support after cardiac surgery aims to take over part of the work of breathing, to provide good pulmonary gas exchange and systemic oxygenation. In addition, respiratory function and peripheral oxygen availability must be monitored continuously.

The criteria for weaning from ventilatory support can be achieved within a few hours in most patients after cardiac surgery. Clinical and respiratory criteria have been used for many years to decide when extubation can be performed safely (Table 2).

The validity of these criteria has been questioned, stimulating a search for more precise indices ${ }^{[5]}$. Although conventional criteria seem appropriate in patients weaned after short periods of mechanical ventilation, inspiratory work of spontaneous

\footnotetext{
Address for correspondence: P. M. Suter, M. D. Division des Soins Intensifs Chirurgicaux, Hòpital Cantonal Universitaire, 1211 Genève 4, Switzerland.
}

breathing seems to be a better indicator for successful weaning after prolonged mechanical support ${ }^{[6]}$. In patients suffering from chronic obstructive pulmonary disease (COPD), Menzies ${ }^{[7]}$ found that successful weaning can be predicted by premorbid level of activity, $\mathrm{FEV}_{1}$, serum albumin level, respiratory rate during $T$-piece trial and negative inspiratory pressure.

Tobin ${ }^{[8]}$ observed that rapid, shallow breathing and paradoxical respiratory movements of the thorax or the abdomen were associated with unsuccessful weaning. The tracheal occlusion pressure at $0 \cdot 1 \mathrm{~s}(\mathrm{P} 0 \cdot 1)$ after onset of occluded inspiration is another new and valuable index ${ }^{[9]}$. The latter has been found to have good predictive value in patients with COPD during acute respiratory failure because it is a good indicator of respiratory muscle strength and fatigue. Sassoon ${ }^{[10]}$ found a good correlation between the value of $P 0 \cdot 1$ and successful weaning in this type of patient. Measurement of oxygen consumption does not seem to be a good indicator of outcome of weaning ${ }^{[11]}$.

Despite our increasing knowledge and a number of newer indices proposed to guide the weaning process, the decision as to when extubation should be performed is difficult in certain situations. In the elderly patient, particular attention has to be given to preoperative pulmonary and cardiovascular function.

\section{Ventilatory techniques for weaning}

The two ventilatory modes usually employed for the postoperative period after cardiac surgery are: controlled mechanical ventilation (CMV) followed by intermittent mandatory ventilation (IMV) with progressively decreasing mechanical rate; or direct transition from CMV to spontaneous breathing.

The advantages and disadvantages of both modes are well known ${ }^{[12-14]}$. As they are not 'ideal', other techniques of mechanical support ventilation are proposed. One of these is inspiratory pressure 
Table I Causes of respiratory dysfunction after cardiac surgery ${ }^{\text {(I) }}$

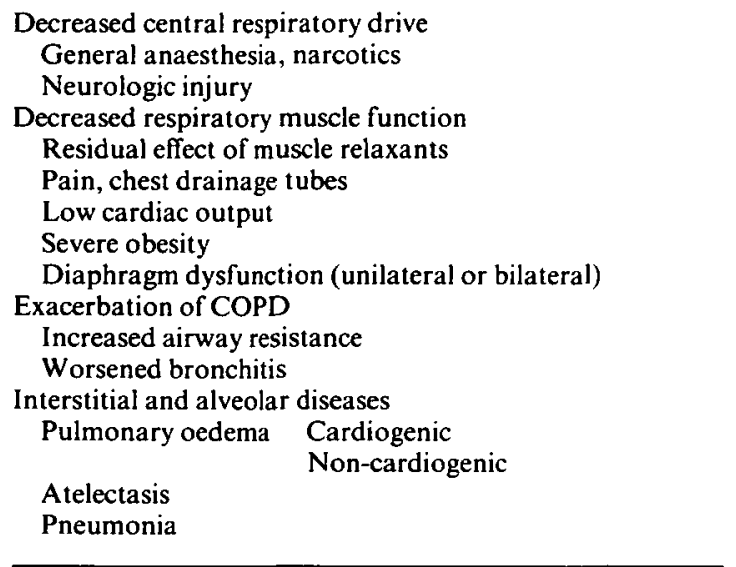

Table 2 Weaning criteria ${ }^{[4]}$

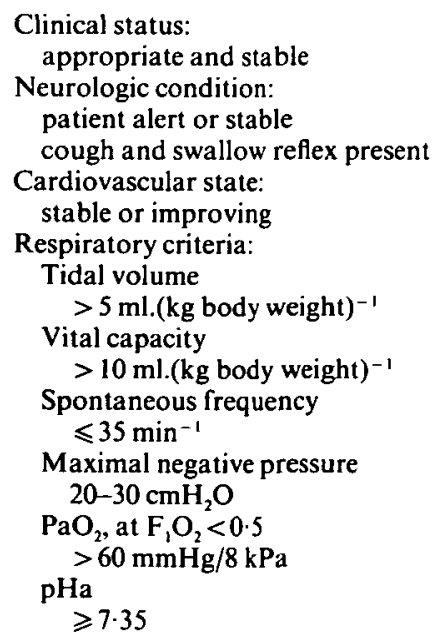

support ventilation (PS) ${ }^{[16]}$. This seems a promising mode during the weaning period, and should be started as soon as the patient's respiratory drive has recovered. PS is frequently better tolerated by the patient than is IMV, possibly partly because it markedly increases the efficacy of spontaneous breathing while reducing the load on the inspiratory muscles $^{[14,15]}$. It may prevent diaphragmatic fatigue by diminishing the work of breathing and oxygen consumption ${ }^{[14,16]}$. It appears to have fewer cardiovascular side-effects than do CMV and IMV $V^{[18]}$.

\section{Frequent causes of weaning failure}

A positive end-expiratory pressure (PEEP) or a continuous positive airway pressure (CPAP) are used frequently to increase the low functional residual capacity, gas exchange surface area and arterial oxygenation ${ }^{[2]}$. CPAP can be applied via an endotracheal tube and continued after extubation with a face mask, and it counteracts efficiently atelectasis and hypoxaemia in a majority of patients. However, CPAP can produce a hyperinflation, secondary to air-trapping, in patients presenting with chronic obstructive pulmonary disease. In addition, the presence of an intrinsic PEEP $\left(\right.$ PEEP $\left._{\mathrm{i}}\right)$ can impose an important load on inspiratory muscles $^{[18]}$. Only a small part of this additional work is performed by CPAP (Fig. 1), the rest has to be provided by the patient. In fact, the static recoil pressure of the respiratory system is the main pressure that must be overcome by the inspiratory muscles (or the respirator) in order to achieve an inspiratory tidal volume. Due to the non-linearity of the pressure-volume relationship, work will increase at higher lung volumes. The presence of PEEP $_{i}$ also dictates that inspiratory muscles must first generate a pressure identical to $\mathrm{PEEP}_{\mathrm{i}}$, before they can start inspiration. Although the application of CPAP during weaning can provide a part of the inspiratory pressure to overcome the effects of PEEP $_{i}$, it may contribute to hyperinflation and increase expiratory work ${ }^{[18]}$. Therefore, the level of CPAP during weaning and after extubation of patients after cardiac surgery must be adapted to the individual response, as assessed by pulmonary gas exchange, respiratory work, tidal volume and frequency.

Recently, respiratory muscle failure has been recognized more frequently as a cause of weaning failure, and a number of therapies have been proposed. Graded respiratory muscle training has been suggested to improve strength and enhance the weaning progress in patients with $\mathrm{COPD}^{[19.20]}$. Nutrition and metabolic disorders such as hypophosphataemia must be appropriately corrected to allow sufficient respiratory muscle function ${ }^{[21.22]}$. Three well-known pharmacologic agents have been shown to improve the strength of the diaphragm in patients with respiratory failure: aminophylline ${ }^{[23]}$, digoxine $^{[24]}$, and dopamine ${ }^{[25]}$. These drugs can be useful in certain situations where respiratory muscle strength is not sufficient to ensure adequate alveolar ventilation during unassisted breathing.

A third cause of weaning failure, which is easily 

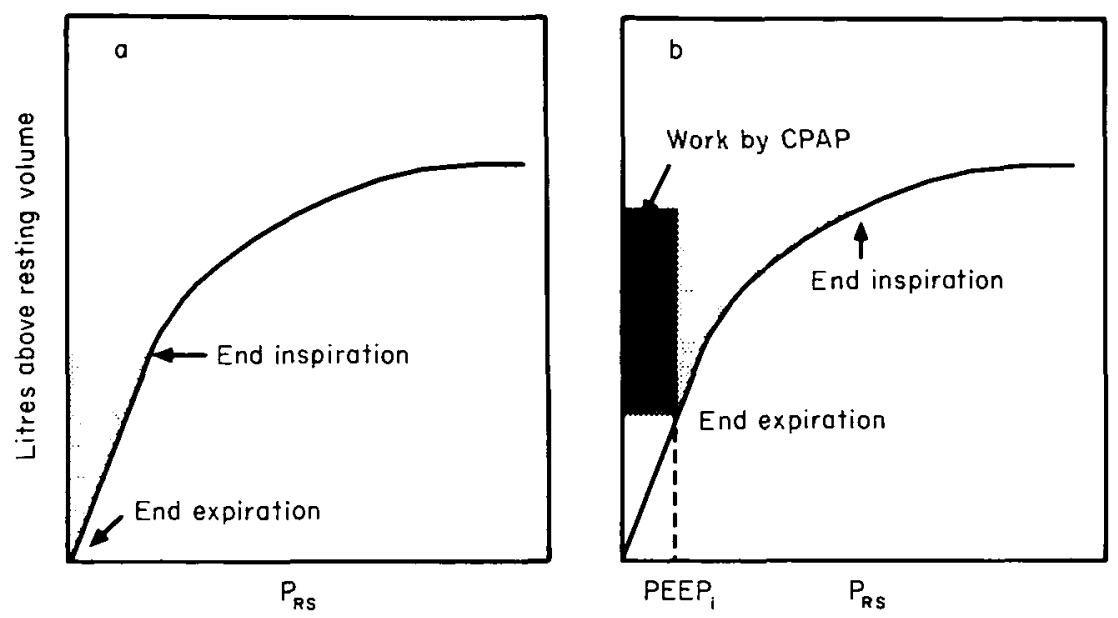

Figure I Relationship between elastic recoil pressure of the respiratory system $\left(\mathrm{P}_{\mathrm{RS}}\right)$ and lung volume above resting volume, in the absence (A), and the presence (B) of intrinsic PEEP (PEEP $)$ or CPAP. The total shaded area represents the elastic work necessary to inflate the lung with an identical tidal volume. The darkly shaded area depicts the reduction of elastic work that could be supplied by CPAP and thereby reduce the burden imposed by PEEP $P_{i}$.

Reproduced from [17] with permission.

overlooked in the patient presenting with an acute exacerbation of COPD, is left ventricular dysfunction $^{[26]}$. In the elderly patient having undergone cardiac surgery, this is usually recognized without delay. Improvement of cardiac function will allow in most cases progressive weaning and extubation.

\section{References}

[1] Matthay MA, Wiener-Kronish JP. Respiratory management after cardiac surgery. Chest 1989; 95: 424-34.

[2] Suter PM, Demottaz V, Hemmer M. Postoperative Beatmungstechnik nach Herzoperationen: Auswirkungen von PEEP und CPAP auf Lungenfunktion und Hämodynamik. Herz 1978; 3: 198-205.

[3] Chenoweth DE, Cooper SW, Hugli TE, Stewart RW, Blackstone EH, Kirklin JW. Complement activation during cardiopulmonary bypass. Evidence for generation of $\mathrm{C} 3 \mathrm{a}$ and $\mathrm{C5a}$ anaphylatoxins. $\mathrm{N}$ Engl $\mathrm{J}$ Med 1981; 304: 497-503.

[4] Sahn SA, Lakshminarayan MD, Petty TL. Weaning from mechanical ventilation. JAMA $1976 ; 235: 2208-12$.

[5] Tobin MJ. Predicting weaning outcome. Chest 1988; 94 : 227-8.

[6] Fiastro JF, Habib MP, Shon BY, Campbell SC. Comparison of standard weaning parameters and the mechanical work of breathing in mechanically ventilated patients. Chest 1988; 94: 232-8.

[7] Menzies R, Gibbons W, Goldberg P. Determinants of weaning and survival among patients with COPD who require mechanical ventilation for acute respiratory failure. Chest 1989; 95: 399-405.

[8] Tobin MJ, Perez W, Guenther SM et al. The pattern of breathing during successful and unsuccessful trials of weaning from mechanical ventilation. Am Rev. Respir Dis 1986; 134: 1111-8.

[9] Murciano D, Boczkowski J, Lecocguic Y, Milic-Emili J, Pariente R, Aubier M. Tracheal occlusion pressure: A simple index to monitor respiratory muscle fatigue during acute respiratory failure in patients with chronic obstructive pulmonary disease. Ann Int Med 1988; 108: 800-5.

[10] Sassoon CSH, Te TT, Mahutte K, Light RW. Airway occlusion pressure: An important indicator for successful weaning in patients with chronic obstructive pulmonary disease. Am Rev Respir Dis 1987; 135: 107-13.

[11] Hubmayr RD, Loosbrock LM, Gillespie DJ, Rodarte JR. Oxygen uptake during weaning from mechanical ventilation. Chest 1988; 94: 1148-55.

[12] Willatts SM. Alternative modes of ventilation. Part $\mathbf{I}$. Disadvantages of controlled mechanical ventilation: Intermittent mandatory ventilation. Intensive Care Med 1985; 11: 5I-5.

[13] Marini JJ, Rodriguez M, Lamb V. The inspiratory workload of patient-initiated mechanical ventilation. Am Rev Respir Dis 1986; 134: 902-9.

[14] Brochard L, Pluskwa F, Lemaire F. Improved efficacy of spontaneous breathing with inspiratory pressure support. Am Rev Respir Dis 1987; 136: 411-5.

[15] Brochard L, Harf A, Lorino H, Lemaire F. Inspiratory pressure support prevents diaphragmatic fatigue during weaning from mechanical ventilation. Am Rev Respir Dis 1989; 139: 513-21.

[16] Kanak R, Fahey P, Vanderwarf C. Oxygen cost of breathing. Changes dependent upon mode of mechanical ventilation. Chest 1985; 87: 126-7.

[17] Murphy DF, Dobb GD. Effect of pressure support of spontaneous breathing during intermittent mandatory ventilation. Crit Care Med 1987; 15: 612-3. 
[18] Gay PC. Rodarte JR, Hubmayr RD. The effects of positive expiratory pressure on isovolume flow and dynamic hyperinflation in patients receiving mechanical ventilation. Am Rev Respir Dis 1989; 139: 621-6.

[19] Pouriat LJ, Lamberto Ch, Fosse JP, Vasseur B, Cupa M. Steady-state breathing pattern responses to small inspiratory resistive loads in COPD patients. Chest 1989; 95: 364-9.

[20j Aldrich TK, Karpel JP, Uhrlass RM, Sparapani MA, Eramo D, Ferranti R. Weaning from mechanical ventilation: Adjunctive use of inspiratory muscle resistive training. Crit Care Med 1989; 17: 143-7.

[21] Benotti PN, Bistrian B. Metabolic and nutritional aspects of weaning from mechanical ventilation. Crit Care Med 1989; 17: 181-5.

[22] Aubier M, Murciano D, Lecocguic Y et al. Effect of hypophosphatemia on diaphragmatic contractility in patients with acute respiratory failure. $N$ Engl J Med 1985; 313: 420-4.

[23] Aubier M, De Troyer A, Sampson M. Macklem PT. Roussos Ch. Aminophylline improves diaphragmatic contractility. N Engl J Med 1981; 305: 249-52.

[24] Aubier M, Murciano D, Viires Net al. Effects of digoxin on diaphragmatic strength generation in patients with chronic obstructive pulmonary disease during acute respiratory failure: Am Rev Respir Dis 1987; 135: 544-8.

[25] Aubier M, Murciano D, Menu Y, Boczkowski J, Mal H, Pariente $R$. Dopamine effects on diaphragmatic strength during acute respiratory failure in chronic obstructive pulmonary disease. Ann Int Med 1989; 110: 17-23.

[26] Lemaire F, Teboul JL, Cinotti L et al. Acute left ventricular dysfunction during unsuccessful weaning from mechanical ventilation. Anesthesiology 1988; 69: $171-9$. 